\title{
IMPRENSA DE FÁBRICA E CULTURAS DE CLASSE NA DITADURA MILITAR EM BLUMENAU-SC (1963-1968)
}

RESUMO: Os jornais de fábrica são periódicos de circulação interna nas principais indústrias têxteis de Blumenau no período de 1963-1968, com abordagem que referencia temáticas ligadas aos trabalhadores e sua relação com as várias esferas de poder, com destaque para assuntos internos da fábrica, política nacional e regional, temáticas femininas, culinária, relações humanas e de trabalho. A proposta desse artigo consiste em problematizar os usos da imprensa fabril como fonte de pesquisa para análise das culturas de classe dos trabalhadores na historiografia social do trabalho no Brasil. Embora os jornais de fábrica apresentassem evidências da tentativa de ingerência dos patrões sobre o mundo do trabalho, também possibilitaram a difusão de ideias que indicavam a experiência cotidiana dos trabalhadores. Com piadas, colunas desportivas e de opinião, os trabalhadores atribuíram novos significados aos acontecimentos políticos e registraram possibilidades de intervenção na sociedade, indicativo da circularidade cultural em sua visão de mundo, constituída por meio de uma ativa participação no processo histórico.

PALAVRAS-CHAVE: Imprensa de Fábrica. Culturas de Classe. Ditadura Militar.

ABSTRACT: Factory's newspapers were periodicals with internal circulation in the main textile industries of Blumenau in the period of 1963 - 1968 They have an approach about the connection

1 Professora titular de História do Brasil República do Departamento de História da Universidade Regional de Blumenau - FURB, Doutora em História Social pela Universidade Estadual de Campinas - UNICAMP <cris@furb.br>. 
between the workers and their relation with all power spheres, especially issues from inside the factory, national and regional politics, female themes, culinary, human relationships and with work. The proposal of this article is to problematize the way to use industry press like a research source to analyze the working class cultures in the social historiography of the work in Brazil. Although the factory newspapers have presented evidence of the interference attempt from the employers in the work world, they also allowed the spread of ideas in the society, what indicates the workers' everyday life experience. With jokes, sports columns and opinion, the workers gave new meanings to the politics' events and recorded intervention possibilities in the society, which indicates their worldview about cultural circulation, composed by an active participation in the historical process.

KEYWORDS: Factory Press. Class Cultural. Military Dictatorship.

\section{Introdução}

As inquietações mais importantes dessa pesquisa convergem com a problemática das fontes na escrita da história social do trabalho no Brasil, por meio da discussão sobre uma fonte que advém dos patrões, em uma conjuntura de autoritarismo e, por outro lado, também contém vestígios da experiência dos trabalhadores. Na dimensão cotidiana existe um campo de força que impõe limites à atuação da classe trabalhadora sim; mas, a despeito de todas as tentativas de controle ditatorial, homens e mulheres encontraram espaços e abriram frestas de liberdade na apartada arena das disputas sociais presentes em sua contemporaneidade.

A possibilidade de potencializar análises históricas com foco em personagens "comuns" por meio de indícios documentais vinculados às fontes da imprensa de fábrica remete ao cotidiano dos trabalhadores. Nesse cotidiano apareciam elementos 
capazes de acionar um equilíbrio para a constante tensão entre limitações e excessos nas relações interpessoais. Essas relações interpessoais, embora não demonstravam contraposições diretas e arriscadas, permitiram a transposição dos possíveis enquadramentos ditatoriais e sua posterior transformação em ações significativas para a preservação de direitos.

Para além da problemática relacionada ao modo de tratamento dessa fonte, ainda cabe dizer que esse tipo de documentação não é uma exclusividade de Blumenau, pois está presente em muitas regiões do Brasil e atravessa períodos históricos diversificados. Portanto, não se trata apenas de colocar Blumenau no mapa da historiografia social do trabalho no Brasil, a pretensão é problematizar o contato dos trabalhadores com o mundo da leitura ou da escrita, para acessar parcialmente o sistema de valores e crenças vinculados à sua própria experiência como ponto de interseção. O município de Blumenau está localizado no nordeste de Santa Catarina, na região conhecida como Vale do Itajaí e, em meados do século XIX, contou com uma expressiva imigração europeia, predominantemente alemã. Em sincronia com a implementação da indústria no Brasil, em 1880, surgiram as primeiras indústrias têxteis na região (Hering, Artex, Karsten), a partir dos artesãos ligados às atividades de tecelagem e fiação. A economia local, ainda hoje, tem a predominância do setor têxtil que, entre 1964-1974, apresentava significativa migração de trabalhadores de outras regiões do Estado, especialmente do litoral e vinculados à cultura de origem luso-brasileira, que veio trabalhar nessas empresas. Diante desse contexto, convém analisar os elementos de convivência dos trabalhadores em seus diferentes grupos sociais, com a intenção de compreender como são constituídas, representadas e mantidas suas culturas de classe (BATALHA, 2004) no tocante ao campo da leitura.

\section{O poder das palavras e a imprensa de fábrica}

É certo que reconstituir o mundo do mesmo modo vivenciado pelas pessoas no passado é impossível e que "não podemos 
traçar os processos mentais durante a leitura. O máximo que podemos fazer é estudar os indícios que remanesceram, dispersos em fontes díspares e nos textos em si" (DARNTON, 2012, p. 528). Ainda assim, é possível seguir na expectativa de mapear algumas possibilidades de acesso às informações disponíveis aos trabalhadores.

O poder das palavras, materializado, sobretudo, pelos jornais, movimentava o mundo do trabalho e, ainda que as fontes das informações fossem escolhidas no âmbito da fábrica ou tivessem vinculação com os patrões, a atribuição de sentidos ao universo da leitura estava associada a uma desafiadora análise de dados que emanou das palavras. Em sua constituição fundamental, a imprensa tornou-se ferramenta imprescindível para os estudos sobre a formulação de ideais, direitos e propostas dos trabalhadores na busca pela transformação de sua condição social e cultural perante a sociedade. O contato com o mundo da leitura ou da escrita instiga os sujeitos históricos na elaboração de um sistema de valores e crenças ligados à sua própria experiência como ponto de interseção, para que possam constituir a si mesmos cultural e socialmente e, na sequência, agir e superar, de forma significativa ou não, as limitações impostas pelas circunstâncias em questão.

O acesso às palavras por parte dos trabalhadores não se restringiu aos livros, devido ao avanço tecnológico e ao incremento de uma diversidade de materiais impressos, que possibilitaram rapidez e eficiência na disseminação da informação. Os panfletos, revistas e almanaques tinham uma circulação veloz e abrangiam um público amplo, não apenas por conta de sua abordagem diversificada e natureza eclética, mas porque atendiam às expectativas de leitores, letrados ou não.

Coexistiam com as revistas, na esteira das possibilidades de acesso à informação, os jornais integrantes de uma imprensa diária e geral, pois, na prática, apresentavam um valor de compra considerado acessível e sua linha editorial continha tipologias temáticas destinadas a vários níveis de alfabetização, com uma divulgação ampla em todo o território nacional. Ainda convém 
mencionar a imprensa jornalística ligada aos periódicos de circulação esparsa, considerados alternativos à grande imprensa, portanto, em sua maioria, desvinculados dos grandes grupos de comunicação que dominavam o jornalismo brasileiro nos anos 1950 e 1960. Sua proliferação se intensificou a partir do Golpe civil-militar de 1964, dado os mecanismos de censura e cerceamento das informações por conta da Ditadura civil-militar que visava direcionar as linhas editoriais dos grandes periódicos, atuação que se agravou a partir de 1968, com a decretação do Al-5 e a própria experiência colaboracionista entre uma parcela da imprensa e órgãos repressivos ${ }^{2}$.

Diferentes da imprensa diária geral e da imprensa alternativa, as publicações de cunho classista e/ou militante, ou imprensa operária, também foram responsáveis pela formulação de redes de difusão cultural entre os trabalhadores brasileiros a partir do final do século XIX. Os periódicos operários eram ferramentas de construção da identidade dos trabalhadores, porque ao descobrirem o poder das palavras, da imprensa em si e da difusão de ideias, passaram a utilizá-las em favor do incremento de sua organização social. Isso ocorreu tanto por intermédio da divulgação de propostas ligadas à militância, quanto para criar, sob seu ponto de vista, uma rede de relações sociais vinculada ao mundo do trabalho e às culturas de classe ${ }^{3}$.

No entanto, em tempos de Ditadura Militar, a maioria dos jornais operários foi suspensa e, no caso de Blumenau, surgiu um tipo de imprensa ligada aos trabalhadores, embora não exclusivamente produzida por eles: os jornais de fábrica e/ou associativos. Eram

2 Discussão detalhada sobre esta temática encontra-se em: KUSHNIR, Beatriz. Cães de guarda: jornalistas e censores, do Al-5 à Constituição de 1988. 2001. 428 p. Tese (Doutorado em História)-Instituto de Filosofia e Ciências Humanas, Universidade Estadual de Campinas, Campinas, 2001.

3 No universo da historiografia social do trabalho no Brasil, Silvia R. F. Petersen, da Universidade Federal do Rio Grande do Sul (UFRGS), realiza instigante pesquisa sobre a circulação da imprensa operária brasileira em contato com sua dimensão global. Estudos que envolvem a Argentina e o Uruguai são efetivados por Mirta Lobato, pesquisadora da Universidade de Buenos Aires (UBA). 
periódicos de circulação interna nas principais indústrias têxteis de Blumenau ${ }^{4}$, em geral, editados mensalmente. Sua abordagem principal referenciava temáticas ligadas aos trabalhadores, além de sua relação com as várias esferas de poder, tanto empresariais, quanto políticas. Não foi por acaso que esses periódicos de fábrica surgiram no pré-golpe civil militar de 1964 e duraram, em média, até 1968, momento que o governo impôs restrições e limites às publicações no Brasil. Esses jornais, obviamente, não expressavam exclusivamente os ideais representativos da opinião da classe trabalhadora e foram gestados em períodos anteriores (1961-63), portanto, denotavam também posições conservadoras, em uma perspectiva de colaboração entre as classes, além de contar com uma interferência nítida dos patrões e diretores de seção. Era inegável que algumas posições divulgadas encontravam "ressonância entre as bases" (WEINSTEIN, 2000, p. 214) e, na ausência de vestígios documentais capazes de indicar o modo como os trabalhadores se apropriavam dos textos que liam nesses periódicos fabris, convém fazer uma análise intensiva das fontes, na expectativa de trazer à tona algumas de suas opções e escolhas na composição de suas culturas de classe.

Ainda assim, mesmo por meio de uma fonte que emana dos patrões, mas tem relação direta com os trabalhadores, mediante adequada metodologia de pesquisa, torna-se viável problematizar os jornais de fábrica. Afinal de contas, quais os documentos percorreram o espaço público e foram produzidos exclusivamente por trabalhadores nesse período histórico? Portanto, "uma variada

4 Município catarinense situado na mesorregião do Vale do Itajaí e entre 1960 e 1968, contava com uma população em torno de 50 mil habitantes. Sua economia era predominantemente associada à indústria têxtil - classificada como o décimo polo têxtil nacional, desdobrada em primeiro produtor de artigos felpudos, de malharia branca, de camisas de malha, de etiquetas bordadas (aproximadamente $63 \%$ da manufatura brasileira); e o segundo produtor de gazes medicinais e de roupas brancas de modo geral. Esses números contribuíram para que Blumenau vigorasse como o primeiro centro industrial de Santa Catarina, com um total de aproximadamente $10 \mathrm{mil}$ trabalhadores (19,2\% da mão de obra total do estado). 
gama de aproximações, distanciamentos e negociações pode se estabelecer" e, com isso, abriam-se margens de liberdade, principalmente porque em uma correlação desigual de forças, fosse com o governo, fosse com os patrões, a "aberta e radical oposição nunca é possível” (GOMES, 2007, p. 47).

Diante de tais ressalvas, aponto para a nítida evidência dos limites da experiência humana, sem praticar o reforço dessas limitações, mas atenta aos modos utilizados pelos sujeitos para alcançar a agência (THOMPSON, 1958) e interceder sobre sua própria história, que não se faz por conta própria ou como classe operária distinta ou apartada das relações com os poderes em questão. A imprensa de fábrica também atuava como força ativa e ingrediente fundamental no processo de ação dos trabalhadores na constituição de seus modos de vida. Claro, um cuidado necessário refere-se a evitar pensar a imprensa sob uma perspectiva teleológica, em busca de um "longo percurso em direção a um tempo mais democrático [...], pois o tempo longo dessa história se recria, se reinventa e se repõe em cada conjuntura" (CRUZ; PEIXOTO, 2007, p. 235-270).

Para além da problemática relacionada ao modo de tratamento desta fonte, ainda cabe dizer que essa tipologia documental não era uma exclusividade de Blumenau, pois está presente em muitas regiões do Brasil $^{5}$ e atravessou períodos históricos diversificados. Portanto, não se trata apenas de colocar Blumenau no mapa da historiografia social do trabalho no Brasil, a pretensão é problematizar o uso das palavras e a incorporação dos hábitos de leitura como atitudes capazes de desenvolver nos leitores-operários a possibilidade de interação com novas ideias para, em última análise, conquistar certa liberdade de pensamento e autonomia, tanto nas relações sociais e comunitárias, como na relação do leitor com os textos que lê e escreve.

5 A problematização dos jornais produzidos pela fábrica da Ford no $A B C$ paulista pode ser vista em: NEGRO, António Luigi. Linhas de montagem: o industrialismo automotivo e a sindicalização dos trabalhadores (1945-1978). 2001. 588 p. Tese (Doutorado em História)-Instituto de Filosofia e Ciências Humanas, Universidade Estadual de Campinas, Campinas, 2001. 
A imprensa de fábrica apresentava uma circulação interna e alcançava o espaço público local, com distribuição gratuita e acesso facilitado às publicações. Os periódicos estavam intimamente vinculados à administração e, em certos casos, enfrentavam sanções e interferências em sua composição editorial ${ }^{6}$. A autoria das colunas estava predominantemente sob a responsabilidade dos trabalhadores do setor administrativo, contudo, constavam ainda colaboradores e colunistas fixos ligados aos demais setores de produção das fábricas. Diante das modulações temáticas constantes e diversificadas das colunas, também apareciam autores que assinavam com pseudônimos. Tal situação era recorrente e representativa da atuação direta dos trabalhadores nos espaços associativos e na elaboração dos jornais, ambos locais de manifestação de sua vida cotidiana. Por isso, faziam críticas ao seu tempo, salvaguardados por pseudônimos e, esse recurso do anonimato, vinculava-se às possibilidades que referenciavam tanto o resguardo do autor quanto os usos da imaginação por parte do leitor.

A ausência do nome real do autor remetia a um fenômeno das relações sociais da fábrica que denotavam uma face da sociedade em questão, na qual de certo modo predominavam relações paternalistas de dependência. A existência de pseudônimos era parte constituinte de uma construção social ainda mais elaborada, porque dava a entender que a identificação de autoria poderia acarretar possíveis situações de tensão para os autores nos setores de trabalho. Além disso, a publicidade inspirava outros colaboradores à publicação de novos textos, sem indicativa de autoria, e transformava-se em um canal de diálogo entre as classes.

6 Por isso, o esforço de análise dessa fonte requer cautela para lidar com os desmentidos dos textos elaborados, levando em consideração os grupos hegemônicos que forneceram verbas para a edição do jornal. Por outro lado, o estudo desses jornais também permitiu reconstituir parte da rede de sociabilidade construída por intermédio das relações de trabalho, em consonância com atividades desportivas e recreativas integradas à própria indústria. 
Assim, embora não seja possível adentrar na minúcia analítica de cada um dos jornais de fábrica e, em consideração às ausências dos próprios números ou de sua preservação, no tocante aos periódicos da natureza mencionada e ao período de maior interesse, havia um total de 152 números publicados entre 1963 e 1968, embora as publicações, em sua maioria, extrapolassem esse período. Em geral, os jornais se encontravam completos, variavam entre 4 e 26 páginas em cada uma de suas edições, ainda que por vezes contivessem lacunas, com a falta de uma e outra página ou então de um e outro mês dentro de suas respectivas séries documentais, assim distribuídas: Informativo Hering, com 15; Noticiário Cremer, com 7; Mensageiro Artex, com 61 e Radar Sulfabril, com 69 edições.

A linha editorial do Informativo Hering, criado em 1963, não era direcionada excessivamente às condições de trabalho, mas enfatizava os estatutos da Associação Atlética e Cultural Têxtil Hering - AACTH (ESTATUTOS, jul. 1964, p. 8) e a divulgação de eventos sociais, aniversários e casamentos, como também a "Página feminina" e as "Rabanadas dos peixinhos", com piadas dos dois "peixes" - símbolo da fábrica - que observavam as situações cômicas ocorridas entre os associados. Para além das piadas, essa seção contemplava sutilmente algumas reivindicações, tais como: "O Irineu teve uma idéia brilhante estes dias, achou que o governo deveria decretar o Sábado Inglês. Nós sugerimos outra coisa que seria mais interessante: a semana inglesa, isto é, não trabalhar no sábado" (RABANADAS, nov. 1964, p. 6). O que importa, nesse caso, não é perscrutar se foi ou não um engano da parte do Irineu, mas destacar a demonstração de conhecimento acerca dos direitos trabalhistas, a ponto de utilizar um humor fino e inteligente, não para diretamente reivindicar direitos, e sim para, ao menos, levantar um breve debate sobre o tema da diminuição da jornada semanal de trabalho.

Já o Noticiário Cremer destacava, em seu primeiro número (NOTICIÁRIO CREMER, dez. 1966, p. 1), que era fruto de colaborações espontâneas e voluntárias, sem especificação dos setores de atuação de seus colaboradores. Sua característica 
editorial era variável, mas algumas colunas prevaleciam ao longo de sua existência: "Sociais", responsável pela divulgação de notas sobre datas comemorativas (aniversários, noivados, casamentos, nascimentos, batismos); "Vamos rir juntos", correspondente à coluna de humor, assinada inicialmente por Ruy Vagner Gaertner; "Página feminina", por Dagmar Heidrich, sua primeira responsável; "Treinamento em marcha" e "Conheça seu ambiente de trabalho" (este último por Werner Kegel), cujo escopo era a difusão de orientações voltadas ao trabalho, para melhorar a produção ou evitar sinistros, bem como apresentar os setores da fábrica; "Página esportiva", por Siegolf Schmitt; "O que vai pelo mundo", de Joerg D. Engmann, em geral sobre assuntos internacionais dos mais diversos e recentes. Três particularidades desse jornal chamavam a atenção: a presença esporádica de poemas/poesias (tanto de trabalhadores quanto de escritores "consagrados"), a quantidade variada de páginas ocupadas por publicações do tipo passatempo (desafios de matemática, curiosidades, cruzadinhas etc.) e a difusão de saberes de cunho instrutivo e de serviços de utilidade pública em pé de página ("Agasalhe menos o seu filho no verão e ofereça-Ihe bastante água fervida ou filtrada, que assim estará prevenindo a desidratação" ou "A difteria, o tétano e a coqueluche são doenças graves. Leve o seu filho ao centro de saúde para ser vacinado") ${ }^{7}$.

\section{O "Coquetel de Fatos" do Misturador e o "Álbum da Família" no Radar Sulfabril}

O Mensageiro Artex, existente desde 1964, contava, por exemplo, com as colunas "Página feminina", de autoria de Andréa (consta somente o primeiro nome); "Sociais", por Miriam Kloch;

7 Em seus estudos sobre o SESI, Barbara Weinstein demonstrou a importância atribuída pela classe patronal às instruções acerca da higiene e das obrigações paternas e maternas acerca dos cuidados familiares (Reconstruindo o operário no lar e na recreação). Mais detalhes em: WEINSTEIN, Barbara. (Re)formação da classe trabalhadora no Brasil, 1920-1964. São Paulo: Cortez; CDAPHIFAN; Universidade São Francisco, 2000. 
e "Página esportiva", de Vitor I. dos Santos. O uso constante de pseudônimos correspondia a uma característica peculiar do periódico e, em geral, os jornais registravam o nome de seus colunistas, mas havia casos em que o autor não era conhecido. Ao longo de sua existência surgiram inúmeras colunas, que apresentavam repetidas trocas de autoria e indicavam uma rotatividade constante em suas características. Acrescente-se a isso a diversidade de temas das edições e um claro direcionamento para assuntos que não estavam circunscritos ao âmbito fabril ou municipal, com uma gama extensa de apontamentos de caráter opinativo acerca de assuntos do cotidiano, curiosidades e política nacional. Além disso, o Mensageiro Artex apresentou uma variação na tiragem entre 1964 e 1968, que ficava entre 1.200 e 2.150 exemplares, com predominância de 1.800 cópias por edição.

Do Mensageiro Artex ecoavam vozes como a do Misturador que, ao referendar os altos índices da inflação brasileira e apontar para os níveis alarmantes atingidos em 1964, como um dos maiores do século $X X$ até aquele momento, soltou o verbo na edição de janeiro. Em sua crítica, tratava o governo João Goulart (1961-1964) como "inapto" e, na sequência, dizia que o presidente "fica às tontas diante do flagelo e, vendo o fracasso do pomposo plano trienal do sr. Furtado, [...] volta a insistir nas tais 'reformas de base' que nem o sr. Goulart sabe ao certo o que sejam e que de tão sovadas e 'chatas' já estão inteiramente desmoralizadas" (MISTURADOR, jan./mar. 1964, p. 11).

Esse autor ou autora da coluna Coquetel de Fatos, com o pseudônimo de Misturador, teceu ásperas críticas que se tornavam compreensíveis à luz das convulsões sociais que lhe atingiam cotidianamente, como a onda inflacionária. Além disso, ciente das consequências ocasionadas pela economia brasileira, na mesma edição de janeiro também fez considerações acerca do "novo salário mínimo, que se propala vir em dobro sobre o atual, [...] [mas] que será puro círculo vicioso, pois há de provocar violenta elevação de preços, que logo anulará a medida" (MISTURADOR, jan./mar. 1964, p. 11). 
Essa passagem do misterioso colunista do mensário Mensageiro Artex remetia a uma questão primordial que precisava ser levada em consideração em suas elaborações textuais: sua própria experiência de vida e o acesso às leituras diferenciadas como responsáveis pela parametrização de suas opiniões. A situação pode ser analisada sob a perspectiva da própria experiência humana - individual ou de grupos sociais -, como um campo relacionado às reações ou respostas mentais $e$ emocionais dos seres humanos a determinados acontecimentos que se relacionam entre si e ocorrem com certa frequência e repetição ${ }^{8}$. No âmago dessa reflexão da experiência como um processo de elaboração pessoal e/ou grupal, cabe pensar que, na mesma edição do jornal, o Misturador prosseguiu sua fala e destacou claramente aquilo que entendia por "inaptidão do governo federal frente à inflação". Além disso, sua conclusão foi taxativa: "por causa da carestia, vão eclodindo greves e mais greves, quase todas atiçadas e garantidas pelo ilegal e subversivo CGT - o famigerado 'Comando de Greves', da ridícula minoria comunista, mas todo-poderoso em face do débil e indeciso governo" (MISTURADOR, jan./mar. 1964, p. 11).

Parte do problema político referenciado pelo Misturador deviase ao fato de que os grupos com os quais Goulart conversava e fazia alianças nesse momento não aceitavam um governo de conciliação. Além disso, estudos têm demonstrado que Jango assumiu o governo numa situação delicada, sobretudo por conta de três aspectos de crise: 1) militar, em função dos levantes no exército; 2) econômico, por conta do descontrole das contas públicas e as dívidas internas e externas do país; e 3) político, devido à ineficácia da implementação das reformas de base.

8 Essa dimensão tem sido estudada com afinco pelos historiadores sociais do trabalho, sobretudo a partir das contribuições de E. P. Thompson, que propõe pensá-la como uma espécie de elaboração que "surge espontaneamente no social, mas não surge sem pensamento. Surge porque homens e mulheres (e não apenas filósofos) são racionais, e refletem sobre o que acontece a eles e ao seu mundo". THOMPSON, Edward Palmer. A miséria da teoria. Uma crítica ao pensamento de Althusser. Rio de Janeiro: Zahar, 1981. p. 16. 
Todavia, João Goulart, em parte, poderia ser considerado um estratégico negociador (FERREIRA, 2003, p. 248).

Essa característica não era considerada na opinião do Misturador, que sentenciou: "tal situação de anarquia nacional, sem que apareça alguém que 'dê um jeito' nisso, leva a gente a concordar, mesmo a contragosto, com o falecido Osvaldo Aranha quando certa feita sentenciou: 'O Brasil é um deserto de homens e de ideias!'” (MISTURADOR, jan./mar. 1964, p. 11). Sua postura política coincidia com as apresentadas nos grandes veículos de informação do período, onde a responsabilidade de todo o caos econômico recaía sobre a suposta falta de requisitos de João Goulart para governar o Brasil e isso fortificou a tese da ingerência presidencial. As falas com esse teor contribuíram, sobremaneira, para a historiografia brasileira indicar a necessidade de contenção de direcionamentos argumentativos que personalizavam a história e atribuíam às figuras políticas a responsabilidade exclusiva pela realização deste ou daquele feito histórico.

Longe de pura e simplesmente concordar ou discordar do colunista, a intenção é inferir acerca da intencionalidade instrutiva dos comentários do Misturador em relação ao seu público leitor em potencial. Seu ponto de vista estava alinhado com os propósitos dos empresários e componentes da diretoria da fábrica, a partir de um posicionamento contrário às greves e direcionado a um ataque ao Estado, representado pela figura do presidente João Goulart. Ora, não era à toa que um jornal de fábrica defensor dos interesses conciliatórios entre patrões e operários tentasse expressar opiniões relacionadas à ordem e à paz social no país.

As posições do Misturador eram corroboradas por outro colunista, o Kalifa, que assinava a autoria da "Página Amena" do Mensageiro Artex. Para o autor, a antiga sede do poder executivo nacional, o palácio do Catete, era uma "espécie de 'casa da sogra' onde o ex-presidente costumava passar umas horas entre um vôo e outro" (KALIFA, maio 1964, p. 4) e o comunismo era um tema que aparecia nas piadas da seguinte forma: "Ideologia: aquele sujeito era tão anti-comunista, que jamais ficou vermelho de vergonha" (MISTURADOR, jan./mar. 1964, p. 6). 
Os temas da política nacional não predominavam na linha editorial do Radar Sulfabril, o mais antigo dos jornais fabris, com o primeiro número lançado em fevereiro de 1963. De caráter razoavelmente fixo, o periódico chegou a promover variações que envolvem desde a troca do autor e manutenção da coluna ou vice-versa, além da mudança dos nomes das colunas. Majoritariamente, os escritos do Radar Sulfabril continham registro de autoria e, no que tange ao universo de assuntos de suas edições, circunscrevia-se aos acontecimentos no âmbito da fábrica: ações da diretoria, funcionários, confraternizações, eventos esportivos ligados à Sociedade Desportiva e Recreativa Sul Fabril (SDR), acontecimentos da cidade e afins.

O Radar Sulfabril, por conta da organização e periodicidade constantes apresenta peculiaridades importantes para lidar com as culturas de classe, sobretudo por conta de sua coluna de entrevistas que, mesmo após sofrer adaptações dos editores, propagava os gostos pela leitura, a origem e preferência cultural e social dos trabalhadores e possibilitou a coleta de dados que recuperavam de algum modo a sociabilidade dos trabalhadores nas fábricas têxteis.

Em seu número de apresentação, o editorial de abertura do Radar Sulfabril mencionava seu antecessor, O Palpiteiro, destinado exclusivamente aos associados da SDR Sul Fabril ${ }^{9}$. O novo jornal, lançado para funcionários e operários da fábrica, com publicação mensal e distribuição no último dia do mês, apresentava matérias que seriam submetidas à "censura" e ao "reparo da Administração" (RODRIGUES, fev. 1963, p. 1). Tal procedimento era constante nos periódicos de fábrica, ainda que existisse alguma vinculação com as associações recreativas. Embora com certo grau de opacidade, também foi possível identificar algumas preferências e escolhas dos próprios trabalhadores na constituição de sua própria cultura.

9 A despeito da intensa investigação, não foi possível encontrar indícios do paradeiro desse periódico nos arquivos locais e tampouco na própria fábrica. 
Ainda na sua primeira edição, o jornal Radar Sulfabril anunciava as colunas e os colunistas colaboradores do mensário. A publicação continha sete seções, organizadas pelo coordenador Osny Serpa, assim distribuídas: Conheça melhor seu ambiente de trabalho, a cargo do sr. Heinz Hartmann; A coluna da CIPA (Comissão Interna de Prevenção de Acidentes), sob responsabilidade de Aurélio Francisco Flores; Esportes, de Wilmar Zoschke; Curiosidades, de Adolar Léo Hermann; Humorismo, de Valmor Buss; Crônica do mês e Sociais, ambas de Lourival Rodrigues.

Aproximadamente 41 colaboradores passaram pelo jornal entre 1963 e 1968 e, após análise inicial, isso indicava uma contínua rotatividade dos autores, situação que se invertia quando se tratava das colunas, que apresentavam uma espécie de constância nas edições. Por isso, antes de descrever a característica das seções convém dimensionar parte da trajetória de alguns colunistas que permaneceram mais tempo, afinal de contas, eram eles os autores das colunas: Aurélio Francisco Flores, Wilmar Zoschke e Adolar Léo Hermann.

Aurélio Francisco Flores iniciou na coluna CIPA, muito comum nesse tipo de periódico, com a função de instruir os trabalhadores e/ou contabilizar os sinistros, permanecendo até março de 1964, portanto, durante um ano. Voltou a colaborar em fevereiro de 1966, na coluna de Esportes, após assumir a função de secretário junto à chapa eleita para conduzir as ações da Sociedade Desportiva e Recreativa Sul Fabril (SDR Sul Fabril), já que a seção se destinava a divulgar as atividades desportivas e eventos de seus associados, onde permaneceu até junho 1966.

Wilmar Zoschke apareceu em fevereiro de 1963 na seção de Esportes e, em março de 1964, devido à nova eleição da SDR que alterou seu secretário, passou para a coluna CIPA. Permaneceu até agosto de 1964, quando pediu demissão da Comissão Interna de Prevenção de Acidentes. Retornou em outubro de 1965 para assumir a coluna de entrevista com trabalhadores, intitulada Álbum da Família, onde permaneceu até fevereiro de 1966, ou seja, durante quatro meses. 
Adolar Léo Hermann colaborava desde o primeiro número, em fevereiro de 1963, com a coluna Curiosidades ${ }^{10}$. O título da seção por si só era capaz de conferir uma boa noção das possibilidades abordadas, todavia, predominavam assuntos que versavam sobre o corpo humano, geografia, história, religião e outros, em uma seara temática que beirava o indescritível, tamanha diversidade. Em novembro de 1965 passou a ser o autor da coluna Notícias de todo o mundo, surgida em agosto de 1965 e que noticiava acontecimentos internacionais, permanecendo nela até janeiro de 1967. A partir daí manteve apenas a coluna Curiosidades e em agosto de 1967 encerrou sua participação, totalizando quatro anos como colunista.

Outros autores surgiram em abril de 1964, como Waldir Estevão, que escrevia a coluna Sociais, responsável pela nominata de aniversariantes, noivados e casamentos, onde permaneceu até fevereiro de 1965, e Guino José Sgrott, com uma seção denominada Relembrando boas maneiras, título representativo de seu conteúdo, pautado em códigos comportamentais socialmente aceitos. Sgrott manteve-se nessa seção até abril de 1967, quando foi substituído por José Maria Mosimann, com a coluna Retocando, de teor semelhante à anterior, com permanência inconstante após 1968.

Desde o princípio, o Radar Sulfabril não mencionava sua tiragem ${ }^{11}$. Sua primeira edição foi mimeografada - conforme observado pela coloração azul de seus textos -, em um processo em que os conteúdos eram datilografados em matrizes e

10 Exemplos específicos: Você sabia que: Blumenau já foi a capital do estado por trinta dias, em 1893?; o corpo humano tem 214 ossos?; cada exemplar do jornal New York Times, dos Estados Unidos, tem 620 páginas, pesando $3,1 \mathrm{~kg}$ ? Cf. HERMANN, Adolar. Curiosidades. O Radar Sulfabril. Blumenau, abr. 1963, p. 1.

11 Até o ano de 1968, o Radar Sulfabril não mencionou sua tiragem mensal, mas os dados de outro periódico de natureza semelhante, o Mensageiro Artex, podem servir de referência, pois no período entre 1964 e 1968 sua tiragem variava entre 1.200 e 2.150 cópias, embora 1.800 cópias por edição fosse o número recorrente. 
manualmente rodados em mimeógrafos, página por página, para compor a edição. E, logo na sequência, passou a ser produzido com o uso de linotipo na versão impressa. Dentre os jornais de fábrica e/ou associativos citados anteriormente, este era o representante mais organizado em termos gráficos e sistematizava em seções as próprias temáticas abordadas. Todavia, apresentava constante alteração dos responsáveis, em uma rotatividade cuja predominância incidia sobre a troca interna de autores nas seções, ao invés da sucessão de autores em cada coluna. Além disso, as colunas, embora esporadicamente sofressem alterações de título, em geral mantiveram a linha editorial de sua antecessora.

A partir de agosto de 1965, o periódico deixou de registrar em seu cabeçalho os nomes dos colaboradores e rompeu com sua estrutura interna razoavelmente estável de colunas fixas. Assim, passou a conter informações ao estilo da imprensa diária, pois noticiava acontecimentos variados, apesar de majoritariamente vinculados à fábrica, como feiras de vestuário, festas de encerramento etc. Surgiram colunas sem autorias declaradas -Aspectos de Blumenau no passado; Tópicos curiosos; Isto é um fato e Trovinhas - e ocorreu uma diversificação acentuada de colunistas - Raulino Busarello, Arno Gomes dos Santos, Lourival Antonio dos Santos, Ronaldo Bauke, O. Schreiber e outros. Em 1967 foi possível observar mudanças no Radar Sulfabril, com a presença de matérias avulsas na página de capa, semelhante à grande imprensa. Isso alterou significativamente os aspectos editoriais e gráficos, sobretudo porque se desvinculou do revezamento de autores conforme seu cargo na diretoria da SDR e contou com uma assessoria jornalística profissional, fator que contribuiu para a perda de sua relação direta com a SDR Sul Fabril.

De modo geral, as seções poderiam ser agrupadas em duas linhas editorias: 1) Instrucional: Coluna Feminina e Relembrando Boas Maneiras, ambas destinadas a propor orientações morais e comportamentais acerca da vida dentro e fora da fábrica para os operários; 2) Cotidiana: Humorismo e Álbum de Família, incumbidas de estimular relações de sociabilidade e convivência mútua no dia a dia dos trabalhadores. 
Na Coluna Feminina predominava uma espécie de discurso padrão para mulheres, com destaque para certos ideais de vida em comum, como o lar, filhos, marido, casamento etc. A colunista, Leonídia Silva, enfatizava boas maneiras e seus textos estavam ancorados no tripé moda, culinária e etiqueta. Desde cedo as mulheres estavam rodeadas de normas para ser uma boa mãe de família e a jovem solteira era treinada a envolver-se com tudo o que estivesse relacionado à administração do lar (GERMER, jan. 965, p. 3). Em caso de seguir tais ensinamentos à risca, dificilmente seria apontada como transgressora das condutas femininas e suas atenções deveriam ser redobradas para evitar que prejudicassem seu desempenho na família. Na tentativa de fomentar esses princípios, as instruções dos jornais de fábrica recorriam a uma listagem de "erros" das mães de família: a preferência aos filhos, em detrimento do marido; a política da "porta fechada" aos amigos do marido; o complexo de limpeza e o "desleixo" no vestir (DEZ, fev. 1964, p. 3). Essas condutas comportamentais costumavam aparecer enumeradas de um a dez, em formato de mandamentos e estavam associadas às ações das mulheres no lar, na expectativa de sugestionar o controle das atividades matrimoniais, a maternidade e as funções de dona de casa. Os textos costumavam estabelecer um contato amigável com as leitoras, incentivavam e aconselhavam sobre detalhes importantes da atuação feminina. O bom humor, alegria, paciência, cordialidade, subserviência e passividade eram as qualidades consideradas inerentes às mulheres. Além de serem estimuladas no ambiente familiar, essas atitudes ganharam o interesse do meio industrial, pois fomentavam aspectos de reciprocidade e boa convivência tanto dentro quanto fora da fábrica.

Dentre outras preciosidades vigoravam indicações comportamentais baseadas em um ideal que deveria ser aprimorado em atenção especial a sua família, colegas e consigo própria. Em primeiro lugar estava o "respeito" e a "consideração" para com os pais, além do "bom humor" nas relações entre irmãos e outros membros da família. Além disso, a jovem deveria se esmerar em desenvolver um "espírito de ordem e de método" 
(SILVA, jan. 1965, p. 3), pois seria julgada pela arrumação de seu quarto e o cultivo da higiene e bons hábitos alimentares. Tal esforço em adequar a juventude operária aos preceitos morais não era uma prática conveniente apenas ao sistema fabril, sobretudo no caso têxtil, diante da predominância feminina. Era também um indicativo que não apenas na indústria era necessário instruir para garantir melhores rendimentos no trabalho, pois a própria família operária brasileira era considerada como desprovida de educação e higiene (WEINSTEIN, 2000, p. 269).

Interligadas à coluna feminina encontravam-se as instruções e boas maneiras, porque "aos olhos das pessoas é mais estimado e apreciado alguém bem educado do que um sábio pobre em civilidade e boas maneiras" (SGROTT, abr. 1964, p. 6). Com essa frase Guino José Sgrott iniciava a coluna "Relembrando Boas Maneiras" do Radar Sulfabril. Entre suas edições publicadas de abril de 1964 a abril de 1967, muitas foram as temáticas, no entanto, o foco eram as questões de cunho civilizatório, voltadas às normas e etiquetas nas condutas sociais, mas também sobre o comportamento no ambiente de trabalho.

Dentre os principais assuntos destinados ao "bem educar", apareceram os seguintes temas: como fazer uma saudação; as refeições - uso de talheres, gestos, bebidas - com destaque para cervejas e vinhos -, brinde, sobremesas; como apresentar pessoas; sobre a feitura e/ou comportamento em festas natalinas, de crianças, debutantes - ou em excursões; como agir em cinemas, teatros, junto dos amigos ou diante de visitas - de familiares, de cerimônias, de parabéns, de recém-nascidos, a doentes, de pêsames e as de surpresa.

Decorrido quase um ano de sua existência, em janeiro de 1965, o Radar Sulfabril apontou a falta de sugestões e questionou os leitores se a coluna "pode continuar assim como está sendo feita, ou deve ser mudada? [...]. Seria um grande prazer se esta coluna soubesse quais são as novas sugestões, palpites e ideias dos seus admiradores" (SGROTT, abr. 1964, p. 6). A partir de então, foi possível perceber com nitidez a mudança de teor em seu conteúdo, pois a partir desse mês, Guino José Sgrott passou 
a escrever também sobre as atitudes indicadas como corretas no ambiente de trabalho. O número de setembro de 1965 interrogou se o "prezado leitor" saberia como proceder no ambiente de trabalho e, na sequência, tratou de realizar inúmeras perguntas com o intuito de fornecer uma série de informações sobre o assunto, sumarizados na edição seguinte, que sentenciava:

Execute o seu trabalho limpo, tendendo sempre à perfeição o quanto possível; respeite a autoridade do superior dentro do serviço, acate e estime os colegas [...]. A pessoa educada e cortês será notada, seja rica ou pobre, branca ou preta, moça ou velha. Proceda, porém, naturalmente, não para que o observem, mas pelo prazer que lhe causará o agir com educação. O cuidado nas roupas é de grande importância. Se você usa uniforme, traga-o sempre limpo e bem cuidado, verificando se porventura faltam botões. Se pode vestir-se à vontade, nunca venha ao serviço sujo, despenteado e com roupas rasgadas. Mesmo que a sua vestimenta se componha de peças humildes, você pode parecer elegante, se estiver limpo, com os sapatos engraxados e aparência de alguém que sabe respeitar-se a si mesmo e aos que o rodeiam. Estes princípios gerais de higiene e apresentação são expostos aqui, quase com exclusividade em relação aos homens, porque a uma mulher não se admite, em hipótese alguma, o menor descuido no que se relaciona ao seu traje habitual, à sua postura quando sentada ou de pé, esteja ela no local de trabalho ou fora dele. (SGROTT, set. 1965, p. 10).

Para os homens predominavam instruções acerca da higiene e dos cuidados de si, elementos nem sequer citados em relação às mulheres, diante do fato de que não era admitida a desmobilização da moral e dos bons costumes prescritos pelos comportamentos sociais do período. O autor dessa coluna sempre constituía narrativas que marcavam a distinção entre homens e mulheres nas concepções morais e condutas públicas. Além disso, os direcionamentos atribuídos ao comportamento feminino reiteravam o acúmulo de funções para as mulheres que atuavam nos setores têxteis desse período e procuravam incentivar as 
trabalhadoras a contribuir com o sustento da família, embora sua função como esposa e mãe perdurasse em tempo integral.

Na coluna "Humorismo" as referências mais importantes eram relacionadas com o cotidiano da fábrica e, claramente, evocavam um tom jocoso: "Coisas impossíveis: O Dalla Rosa (Chimbica) fazer regime para emagrecer. A Niniva (Corte Malha) fazer dieta. O João contar uma piada em um minuto. O Canjica não chorar quando é repreendido pelo Haroldo. O Tijucano chupar cana" (BUSS, out. 1963, p. 6). Entre anedotas e brincadeiras, também apareciam críticas que compunham um quadro sutil de situações ligadas às dificuldades ou aceitações do trabalhador em relação às suas atividades diárias: "Entre amigos! - Foi nesta fábrica que tive o maior desgosto de minha vida. - Como foi isso Wilmar Pereira? -É que entrei para pedir emprego... e me deram" (BUSS, out. 1963, p. 6).

Artifício literário interessante foram as previsões emitidas em torno do horóscopo do mês:

Os nascidos em março, jamais nascem em outros meses do ano. São pessoas que tem acentuado gosto pela moda, e, por isto, passam a vida "incomodando". As mulheres tem ligeira preferência pelos homens, e estes só se casam com mulheres. Os que nascem neste mês, são pessoas de cultura e gostam muito de cultivar hortaliças. As mulheres serão grandes pintoras e viverão "pintando o sete". Os homens terão grande tendência para o canto, e passarão a vida "cantando" nos ouvidos do belo sexo. Seus dias preferidos são trinta e trinta e um do mês, pois nesses dias recebem o ordenado (ou fazem vale). Dias de sorte dos nascidos nesse mês: domingos, dias santos, feriados e dias de férias. (POLATI, fev. 1966, p. 12).

As piadas faziam variações ligadas a um anedotário que utilizava expressões-chave para vigorar, por outro lado, continham referências a uma série de situações de trabalho, como o dia preferido do mês por conta do recebimento do salário e a alegria, ou melhor, a sorte de usufruir os dias especiais em que não era 
necessário trabalhar, portanto, também demonstravam parte do cotidiano e das culturas de classe dos trabalhadores.

A prestigiada coluna "Álbum da Família", que foi publicada de 1963 a 1972, era uma das principais do jornal, pois era composta pelas entrevistas realizadas com funcionários, tanto do setor administrativo quanto da produção da Indústria Têxtil Sul Fabril S/A. Seu objetivo era compor um quadro dos trabalhadores e caracterizar sua relação com o trabalho e as formas de sociabilidade. A escolha do entrevistado apresentava um caráter aparentemente democrático e ocorria por meio de sorteio, realizado sempre no último sábado de cada mês no pátio da empresa. Em oito anos e seis meses de publicações seguidas, permaneceu sob a responsabilidade dos seguintes colunistas: Osny Serpa (julho de 1963 a outubro de 1964), Haroldo Germer (novembro de 1964 a setembro de 1965), Wilmar Zoschke (outubro de 1965 a fevereiro de 1966), Lourival dos Santos (março a dezembro de 1966), Ilson Curtipassi (janeiro a dezembro de 1967) e Espério Campestrini (janeiro de 1968 a janeiro de 1972).

As entrevistas eram realizadas por meio de perguntas diretas dos entrevistadores, conforme procedimento adotado por Lourival A. dos Santos e Ilson Curtipassi enquanto foram responsáveis pela coluna, entre 1966 e 1967. Essa forma de entrevistar indicava uma participação oral transformada em escrita pelos autores e isso possibilitou a compreensão de certas formas de apropriação e gestão da informação por parte dos sujeitos sociais analisados.

Durante a existência da coluna "Álbum da Família" foram realizadas 103 entrevistas, das quais foi possível acessar 95, com a ausência de oito, devido às falhas na série documental - números incompletos ou não preservados. Desse montante, $40 \%$ dos trabalhadores entrevistados eram do sexo masculino (38) e $60 \%$ do feminino (57). A porcentagem superior de mão de obra feminina na indústria têxtil era considerada natural, dado ao fato de que as mulheres predominavam nos setores de fiação e costura, ambos fundamentais ao setor produtivo têxtil, conforme já mencionado. 
Ainformação referente ao local de nascimento dos trabalhadores apresentava um índice de $21,05 \%$ de desconhecimento e foi possível identificar que dos $78,95 \%$ restantes, $17,89 \%$ eram naturais de Blumenau e a maioria, $61,06 \%$, advinha de municípios que compõem o Médio e Alto Vale do Itajaí e o litoral do estado de Santa Catarina. Esses indícios representavam bem a expressiva migração para a cidade de Blumenau verificada a partir da década de 1950 e faziam cair por terra o ideal de germanismo como parâmetro de identificação da economia local.

Quanto aos setores de trabalho na indústria, existia uma quantidade de registro majoritária, dado que remetia a uma espécie de preocupação do entrevistador em perguntar e/ou dos entrevistados em responder sobre sua atividade profissional. Sem adentrar nas minúcias do universo em questão, tamanha era a diversidade das atividades fabris, apenas em 7,36\% (7) das edições da coluna "Álbum da Família" não havia declaração acerca da atividade específica ou setor industrial de atuação; 11,57\% (11) pertenciam ao setor administrativo da fábrica e atuavam nos Departamentos de serviços gerais, vendas, relações industriais, pessoal, contabilidade, escritório, recepção e similares. Todavia, importa destacar que da soma total das entrevistas, $81,07 \%$ dos trabalhadores eram do setor de produção ou do 'chão de fábrica', com destaque para os setores de Costura, com 24,21\% (23); Corte e expedição de Algodão ou Malha, com 13,68\% (13); e Estamparia, Tinturaria e Tecelagem com 4,21\% (4) cada.

Esses fatores denotavam a importância da coluna "Álbum da Família" nos periódicos de fábrica e/ou associativos, justamente porque possibilitam a reconstituição de situações cotidianas a partir da própria fala dos trabalhadores urbanos. E, ainda que fossem filtradas e escolhidas pelos entrevistadores e editores na composição final do texto, possibilitam o estudo e análise dos acontecimentos do dia a dia mobilizados pelo entrevistado em relação à sua atuação profissional e social.

Além disso, havia uma constante menção dos entrevistados na coluna "Álbum da Família" para a preferência de leitura dessas entrevistas e da própria coluna do humorismo, indicativo 
da receptividade e identificação dos leitores com seus colegas de trabalho e as temáticas em pauta. Esses depoimentos demonstravam que a maior parte dos entrevistados classificava a leitura como um passatempo, ou seja, como um entretenimento para o tempo livre: Maria Dulce Kunel incluiu o hábito de ler como passatempo preferido; Waldir Estevão (departamento de pessoal) afirmava que em seu tempo livre "lê bastante" (ZOSCHKE, dez. 1965, p. 3); Walmor Passold indicava: "Meu passatempo preferido é a leitura. Leio qualquer coisa" (SANTOS, nov. 1966, p. 3); Raulino Busarello (auxiliar de escritório) voltou à juventude e declarou: "A minha mocidade, comecei-a, entre os livros e a catequese... Gosto muito de ler. Se pudesse passaria o tempo todo lendo" (SANTOS, out. 1966, p. 3); Alcedina da Silva (corte de malha) foi ainda mais ousada e declarou: "é à leitura que me dedico quase em todas as horas de folga" (SANTOS, maio 1966, p. 3). As declarações dos entrevistados indicavam a leitura como um hábito que, por sua vez, não excluía outras formas de sociabilidade, mas que, no entanto, não foram citadas no Álbum da Família por conta da importância do reforço da leitura como uma prática cotidiana. Portanto, a leitura coexistia com outras formas de sociabilidade ligadas à prática desportiva e recreativa.

Todavia, as falas do "Álbum da Família" que faziam referência ao gosto pela leitura demonstravam que os trabalhadores também se tornaram leitores e atribuíram significações àquilo que leem em conexão direta com a elaboração de conhecimentos, base da formação da consciência de si enquanto ser humano atuante em sociedade. Ler, portanto, não era uma atividade meramente receptiva, tratava-se de um ato criativo e dotado de vida própria, por isso, sua prática estava estreitamente vinculada ao prazer e à satisfação de adentrar em um universo de possibilidades que permitia a criação de estratégias múltiplas de leitura de mundo.

Em alinhamento com o Radar Sulfabril, os outros periódicos de fábrica também faziam referência à importância da leitura, fator que demonstrava uma relação com a escrita como guardiã de um poder inestimável. Além disso, também era um meio de transmissão de conhecimento aos trabalhadores e frequentemente 
eram publicadas frases de estímulo à leitura: "Desenvolva a sua inteligência, deleitando seu espírito, lendo um bom livro" BIBLIOTECA, jan./fev. 1969, p. 8) e "leitura sadia que eleva o espírito" (SPINNER, dez. 1965, p. 12). Para além da questão do 'saber é poder', tais discursos presentes nos jornais de fábrica não eram apenas meros recursos utilizados pelos editores para estímulo à leitura como fortalecedora do "espírito", pois também expressavam aspectos da aplicabilidade do fenômeno da leitura à vida diária dos sujeitos históricos.

Em alguns artigos esparsos apareciam recados explícitos para cultivar o hábito da leitura nos momentos de descanso. Sob a justificativa de que "só se conserva na ignorância quem quer", eram frequentes as sugestões de gêneros específicos para que os trabalhadores não lessem apenas romances, mas também obras "ilustrativas" e formadoras de opinião, com um arremate sugestivo: "Lembre-se do repetido adágio: 'O homem que lê vale mais"' (LEIA, mar. 1968, p. 8). Estava incorporada nessa proposição um ideal de ser humano melhor qualificado por meio da leitura, e existia uma insistência em destacar os processos de ler articulados a uma “ilustração", responsável pelo esclarecimento do leitor perante o mundo. Portanto, a incorporação dos hábitos de leitura era compreendida pelos autores dos jornais de fábrica como um ato capaz de desenvolver nos leitores a possibilidade de absorção de novas ideias para conquistar certa liberdade de pensamento e autonomia. Por outro lado, também era conveniente aos patrões o incentivo à leitura para gerar uma predisposição nos trabalhadores em torno do desenvolvimento de possibilidades instrutivas para especialização da mão de obra.

É certo que os efeitos do ato de ler também apresentavam um viés educativo e algumas pessoas referiam-se aos livros como "mestres portáteis" (LIVROS, jan./fev. 1972, p. 21) ou como prática que ocupa uma posição inconfundível no desenvolvimento educacional. A possibilidade de conhecimento estava vinculada a uma multiplicidade de dimensões, mas a proposta centrava-se na união entre cultura geral e instrução. 


\section{Considerações Finais}

Os jornais de fábrica e/ou associativos eram suportes privilegiados da circulação de saberes entre os trabalhadores urbanos das indústrias têxteis de Blumenau. As temáticas editadas nos periódicos demonstraram as possibilidades de contato dos trabalhadores com as várias esferas de poder - empresarial, associativo, político - e surgiram em um período próximo ao Golpe civil-militar de 1964, com duração média até 1968, quando iniciaram restrições mais intensas às publicações no Brasil.

A força da leitura atribuiu novos significados à vida cotidiana dos trabalhadores urbanos de Blumenau e representava a importância da circularidade cultural em sua visão de mundo. As fábricas e associações de trabalhadores buscavam editar os periódicos Mensageiro Artex, Noticiário Cremer, Radar Sulfabril e Informativo Hering, que incentivaram a leitura como meio para o engrandecimento do espírito humano e geração de autonomia. A composição dos jornais de fábrica e/ou associativos pode ser entendida como vetor da cultura e auxiliar da constituição, estímulo e manutenção de certa comunidade de leitores entre os trabalhadores urbanos de Blumenau nas décadas de 1960 e 1970.

Nessa complexa teia dos fios do cotidiano se entrelaçaram temáticas de leitura relacionadas às curiosidades, instruções para a vida doméstica/familiar, seções de perguntas e respostas, enfim, saberes enciclopédicos, bem como expressões literárias emanadas dessas fontes, a exemplo de contos, poemas e romances de folhetim, pois pareceram constituir parte significativa das preferências dos trabalhadores-leitores. Suas próprias falas indicavam a leitura como um hábito e, ainda que nos discursos do próprio jornal de fábrica predominasse o incentivo à leitura, tal prática era vigente entre os trabalhadores, haja vista o hábito de leitura dos jornais internos das indústrias.

A leitura não era um elemento isolado nas culturas de classe dos trabalhadores e o estudo sistemático dos jornais de fábrica possibilita que certas questões do cotidiano dos trabalhadores se tornem palavras e mobilizem elementos representativos da vida 
dos trabalhadores para perscrutar aspectos da vulnerabilidade dos regimes autoritários, porque não há sociedade, por mais rígida que seja, capaz de impedir a sobrevivência de aspectos culturais engendrados pela vontade humana.

\section{Referências Bibliográficas}

BATALHA, Claudio H. M.; SILVA, Fernando Teixeira da; FORTES, Alexandre (Org.). Culturas de classe: identidade e diversidade na formação do operariado. Campinas: Editora da Unicamp, 2004.

CRUZ, Heloisa de Faria.; PEIXOTO, Maria do Rosário da Cunha. Na oficina do historiador: conversas sobre história e imprensa. Projeto História, São Paulo, n. 35, p. 235-270, dez. 2007.

DARNTON, Robert. O diabo na água benta, ou A arte da calúnia e da difamação de Luís XIV a Napoleão. São Paulo: Companhia das Letras, 2012. p. 528.

FERREIRA, Jorge. O governo Goulart e o golpe civil-militar de 1964. In: FERREIRA, Jorge; DELGADO, Lucilia de A. Neves (Orgs.). O Brasil republicano. Rio de Janeiro: Civilização Brasileira, 2003. v. 3.

GOMES, Angela de Castro. Cultura política e cultura histórica no Estado Novo. In: ABREU, Martha; SOIHET, Raquel; GONTIJO, Rebeca (Orgs.). Cultura política e leituras do passado. Rio de Janeiro: Civilização Brasileira; Faperj, 2007.

KUSHNIR, Beatriz. Cães de guarda: jornalistas e censores, do Al-5 à Constituição de 1988. 2001. 428 p. Tese (Doutorado em História)Instituto de Filosofia e Ciências Humanas, Universidade Estadual de Campinas, Campinas, 2001.

NEGRO, António Luigi. Linhas de montagem: o industrialismo automotivo e a sindicalização dos trabalhadores (1945-1978). 2001. 588 p. Tese (Doutorado em História)-Instituto de Filosofia e Ciências Humanas, Universidade Estadual de Campinas, Campinas, 2001. 
THOMPSON, E. P. Agency and choice - I (A replay to criticism). The New Reasoner, n. 5, p. 89-106, summer, 1958.

THOMPSON, Edward Palmer. A miséria da teoria. Uma crítica ao pensamento de Althusser. Rio de Janeiro: Zahar, 1981.

WEINSTEIN, Barbara. (Re)formação da classe trabalhadora no Brasil, 1920-1964. São Paulo: Cortez; CDAPH-IFAN; Universidade São Francisco, 2000.

\section{Fontes Documentais:}

BIBLIOTECAAlwin Schrader. Movimento de Janeiro de 1969. Noticiário Cremer, Blumenau, jan./fev. 1969.

BUSS, Valmor. Humorismo. O Radar Sulfabril, Blumenau, out. 1963. DEZ erros de uma mãe de família. Mensageiro Artex, Blumenau, fev. 1964.

ESTATUTOS da Associação Atlética e Cultural Têxtil Hering. Informativo Hering, Blumenau, jul. 1964.

GERMER, Haraldo. O álbum da "família". Radar Sulfabril, Blumenau, jan. 1965.

HERMANN, Adolar. Curiosidades. O Radar Sulfabril, Blumenau, abr. 1963.

KALIFA (pseudônimo). Página amena. Mensageiro Artex, Blumenau, maio 1964.

LEIA, meu amigo! O Radar Sulfabril, Blumenau, mar. 1968.

LIVROS, mestres portáteis. Noticiário Cremer, Blumenau, jan./fev. 1972.

MISTURADOR (pseudônimo). Coquetel de fatos. Mensageiro Artex, Blumenau, jan.; mar. 1964. 
NOTICIÁRIO Cremer. Blumenau, dez. 1966.

POLATI, J. Humorismo. O Radar Sulfabril, Blumenau, fev. 1966.

RABANADAS dos peixinhos. Informativo Hering, Blumenau, nov. 1964.

RODRIGUES, Lourival. À guisa de prefácio. O Radar Sulfabril, Blumenau, fev. 1963.

SANTOS, Lourival dos. O álbum da família. O Radar Sulfabril, Blumenau, maio; out; nov. 1966.

SGROTT, Guino José. Relembrando boas maneiras. O Radar Sulfabril, Blumenau, abr. 1964; set. 1965.

SILVA, Leonídia. A jovem dentro da família. O Radar Sulfabril, Blumenau, jan. 1965.

SPINNER, Erica. Biblioteca escolar. Informativo Hering, Blumenau, dez. 1965.

ZOSCHKE, Wilmar. O álbum da família. O Radar Sulfabril, Blumenau, dez. 1965.

Recebido em maio de 2016. Aprovado em janeiro de 2017. 